\title{
POLA SEBARAN TITIK PANAS (HOTSPOT) SEBAGAI INDIKATOR TERJADINYA KEBAKARAN HUTAN DAN LAHAN DI KABUPATEN ACEH BARAT
}

\author{
Hotspot Distribution Pattern As an Indicator of Forest and Land Fires in West Aceh District
}

Bambang Hero Saharjo $^{* *}$ dan Muhammad Rizki Ananda Nasution ${ }^{2}$

(Diterima 22 Februari 2021 /Disetujui 8 Juni 2021)

\begin{abstract}
One of the provinces in Indonesia that experiences forest and land fires every year is Aceh Province. Aceh Barat District is one of the districts in Aceh Province where forest and land fires occur every dry season. Forest and land fires prevention can be done by utilizing hotspot data for analysis using geographic information systems (GIS). This research aims to analyze the distribution of hotspots and the correlation between rainfall and hotspots as an indicator of the occurrence of forest and land fires in West Aceh Regency in 2014-2019. This research uses MODIS LAPAN hotspots data, land cover distribution maps, peat land distribution maps, administrative maps and rainfall data from BMKG. The correlation between rainfall data and hotspot data was carried out by the bivariate pearson correlation test. The resuls of the research found that there were 576 hotspots in West Aceh Regency from 20142019. The district with the highest number of hotspots is in Samatiga District, namely 131 hotspots. The most dominant hotspots are in the peatland cover, as much as $64 \%$ and in the swamp scrub land cover area with 126 hotspots. Correlation test results show that rainfall with a negative correlation, that the decrease in rainfall is followed by an increase in hotspots.
\end{abstract}

Keywords: Aceh Barat, fires, GIS, hotspot, rainfall

\begin{abstract}
ABSTRAK
Salah satu provinsi di Indonesia yang mengalami kebakaran hutan dan lahan setiap tahunnya adalah Provinsi Aceh. Kabupaten Aceh Barat merupakan salah satu kabupaten yang berada di Provinsi Aceh yang sering terjadi kebakaran hutan dan lahan setiap musim kemarau. Pencegahan kebakaran hutan dan lahan dapat dilakukan dengan memanfaatkan data titik panas untuk dianalisis dengan menggunakan Sistem Informasi Geografis (SIG). Penelitian ini bertujuan menganalisis sebaran titik panas dan hubungan curah hujan dengan titik panas sebagai indikator terjadinya kebakaran hutan dan lahan di Kabupaten Aceh Barat pada tahun 2014-2019. Penelitian ini menggunakan data titik panas NASA MODIS, peta sebaran penutupan lahan, peta sebaran lahan gambut, peta administrasi dan data curah hujan dari BMKG. Hubungan antara data curah hujan dan data titik panas dilakukan uji korelasi bivariate pearson. Hasil penelitian ditemukan sebanyak 576 titik panas di Kabupaten Aceh Barat dari tahun 2014-2019. Kecamatan dengan jumlah titik panas terbanyak berada di Kecamatan Samatiga yaitu sebanyak 131 titik panas. Titik panas paling mendominasi di tutupan lahan gambut sebanyak $64 \%$ dan daerah penutupan lahan belukar rawa sebanyak 126 titik panas. Hasil uji korelasi menunjukkan curah hujan dengan titik panas tidak memiliki korelasi dengan arah korelasi negatif, bahwa penurunan curah hujan diikuti dengan kenaikan titik panas.
\end{abstract}

Kata kunci: curah hujan, Kabupaten Aceh Barat, lahan gambut, penutupan lahan, titik panas

\footnotetext{
${ }^{1}$ Departemen Silvikultur, Fakultas Kehutanan dan Lingkungan, IPB University

* Penulis korespondensi:

e-mail: saharjobambangh@gmail.com

${ }^{2}$ Mahasiswa Sarjana Departemen Silvikultur, Fakultas Kehutanan dan Lingkungan, IPB University
} 


\section{PENDAHULUAN}

Kebakaran hutan merupakan kejadian pembakaran yang penjalarannya bebas pada areal yang tidak direncanakan serta menggunakan bahan bakar alam dari hutan seperti serasah, rumput, ranting atau cabang pohon mati, pohon mati yang tetap berdiri, log, tunggak pohon, gulma, semak belukar, dedaunan dan pohonpohon (Saharjo 2003). Kebakaran hutan umumnya disebabkan oleh dua faktor, yaitu faktor alam dan faktor manusia. Tetapi, umumnya kebakaran hutan dan lahan di Indonesia terjadi karena tingkah laku dari manusia. Kebakaran hutan yang terjadi biasanya disebabkan karena teknik yang paling murah, mudah dan cepat dilakukan oleh masyarakat dalam mempersiapkan lahannya. Setiap tahunnya kebakaran hutan dan lahan di Indonesia memiliki kecenderungan mengalami peningkatan. Data Statistik Kementerian Lingkungan Hidup dan Kehutanan (KLHK) Republik Indonesia menyebutkan total taksiran luas kebakaran hutan dan lahan di Indonesia menurut mengalami peningkatan dari 165,483.92 hektar pada tahun 2017 menjadi 529,266.64 hektar pada tahun 2018. Selanjutnya luas kebakaran hutan dan lahan di tahun 2019 kembali mengalami peningkatan yaitu menjadi 1,649,258 hektar.

Salah satu provinsi di Indonesia yang mengalami kebakaran hutan dan lahan setiap tahunnya adalah Provinsi Aceh. Wilayah Barat-Selatan di Provinsi Aceh merupakan wilayah yang memiliki potensi kebakaran hutan dan lahan setiap tahun, hal ini terjadi karena di wilayah tersebut memiliki area gambut dan hutan semak belukar dalam hamparan yang luas. Kabupaten Aceh Barat merupakan salah satu kabupaten yang berada di Provinsi Aceh yang sering terjadi kebakaran hutan dan lahan setiap musim kemarau. Banyak perusahaan yang menanam sawit di lahan gambut dan melakukan pembersihan lahan dengan cara pembakaran sehingga berpotensi terhadap kebakaran hutan dan lahan. Hal ini menyebabkan Kabupaten Aceh Barat menjadi daerah yang rawan terhadap kebakaran hutan dan lahan, baik yang disebabkan oleh kelalaian masyarakat maupun kelalaian pihak perusahaan. Fenomena serupa juga terjadi pada ekosistem hutan gambut di Trumon dan Aceh Singkil. Sebagian lahan gambut dengan total luas 169,000 ha atau $61.6 \%$ lahan gambut di Aceh telah beralih fungsi akibat penebangan, kebakaran hutan dan lahan, bencana gempa bumi serta tsunami (Wahyunto et al. 2005).

Informasi dalam pencegahan dan pengendalian kebakaran melalui deteksi dini saat ini sudah mulai banyak disosialisasikan secara transparan kepada masyarakat. Salah satunya informasi melalui titik panas yang didapatkan dari data penginderaan jauh melalui data satelit. Berdasarkan peraturan Menteri Lingkungan Hidup dan Kehutanan nomor P.32/MenLHK/Setjen/ Kum.1 /3/2016 tentang pengendalian kebakaran hutan dan lahan, titik panas atau hotspot adalah istilah untuk sebuah pixel yang memiliki nilai temperatur di atas ambang batas (threshold) tertentu dari hasil interpretasi citra satelit, yang dapat digunakan sebagai indikasi kejadian kebakaran hutan dan lahan. Data satelit yang biasa digunakan untuk mendeteksi titik panas (hotspot) milik Lembaga Penerbangan dan Antariksa Nasional
(LAPAN) adalah TERRA, AQUA dengan sensor MODIS (Moderate Resolution Imaging Spectroradiometer) (Giglio et al. 2016). Pencegahan kebakaran hutan dan lahan di Kabupaten Aceh Barat dapat dilakukan dengan memanfaatkan data titik panas dan data pendukung lainnya untuk dianalisis dengan menggunakan Sistem Informasi Geografis (SIG) dan teknologi penginderaan jauh (remote sensing), sehingga pemadaman kebakaran hutan dan lahan dapat dilakukan lebih cepat. Penelitian ini bertujuan untuk menganalisis sebaran titik panas (hotspot) dan hubungan curah hujan dengan titik panas (hotspot) sebagai indikator terjadinya kebakaran hutan dan lahan di Kabupaten Aceh Barat pada tahun 2014-2019.

\section{METODE PENELITIAN}

\section{Waktu dan Tempat Penelitian}

Penelitian ini dilaksanakan dimulai pada bulan November 2020 sampai Januari 2021. Pengolahan dan analisis data dilakukan di Laboratorium Kebakaran Hutan dan Lahan, Departemen Silvikultur, Fakultas Kehutanan dan Lingkungan, Institut Pertanian Bogor.

\section{Alat dan Bahan Penelitian}

Alat yang digunakan dalam penelitian adalah alat tulis, laptop yang dilengkapi dengan perangkat lunak ArcGIS 10.4 untuk pengolahan data dalam format Sistem Informasi Geografis (SIG), aplikasi MINITAB 18 serta Microsoft Office 2010 untuk pengolahan tabulasi dan grafik. Data yang digunakan sebagai bahan di dalam penelitian adalah data sekunder persebaran titik panas NASA MODIS dari tahun 2014 - 2019, peta sebaran penutupan lahan, peta sebaran lahan gambut yang diperoleh dari Badan Pemantapan Kawasan Hutan (BPKH) Provinsi Aceh, peta administrasi Kabupaten Aceh Barat yang di unduh di website Geospasial untuk Negeri (http://tanahair.indonesia.go.id/) dan data curah hujan bulanan tahun 2014-2019 di Kabupaten Aceh Barat yang bersumber dari Badan Meteorologi Klimatologi dan Geofisika (BMKG) Cut Nyak Dhien.

\section{Metode Pengumpulan Data}

Kegiatan penelitian dimulai dengan melakukan pengumpulan alat dan bahan penelitian yang dibutuhkan dari berbagai sumber. Data sebaran titik panas Kabupaten Aceh Barat diperoleh dari NASA MODIS dari tahun 2014 - 2019, peta sebaran penutupan lahan, peta sebaran lahan gambut yang diperoleh dari Badan Pemantapan Kawasan Hutan (BPKH) Provinsi Aceh, peta administrasi Kabupaten Aceh Barat yang di unduh di website Geospasial untuk Negeri (http://tanahair.indonesia.go.id/) dan data curah hujan bulanan tahun 2014-2019 di Kabupaten Aceh Barat yang bersumber dari Badan Meteorologi Klimatologi dan Geofisika Cut Nyak Dhien. 


\section{Prosedur Analisis Data}

Analisis yang digunakan dalam penelitian adalah analisis deskriptif dan statistik. Langkah awal dalam pengolahan data yaitu pengklasifikasian data titik panas menurut waktu (tahun dan bulan). Pemetaan sebaran titik panas di Kabupaten Aceh Barat pada tahun 20142019 menggunakan data titik panas NASA MODIS dengan tingkat kepercayaan $\geq 50 \%$ dan melakukan overlay pada data titik panas dengan peta administrasi Kabupaten Aceh Barat menggunakan fungsi clip di perangkat lunak ArcGis 10.4. Selanjutnya, proses data spasial dilakukan terhadap peta digital penutupan lahan dan sebaran lahan gambut dengan titik panas Aceh Barat dengan menggunakan fungsi intersect. Proses ini akan menghasilkan attribute gabungan titik panas, penutupan lahan, sebaran lahan gambut dan peta administrasi. Jumlah titik panas selanjutnya dianalisis dari yang paling banyak hingga paling sedikit disetiap tahun dan bulan dari tahun 2014-2019 pada software Microsoft Excel. Penyajian hasil perhitungan data disajikan dalam bentuk grafik, tabel dan layout peta data titik panas. Tahap terakhir yaitu dilakukan uji analisis statistik dengan menggunakan aplikasi MINITAB 18 dengan merekapitulasi data curah hujan dan titik panas dengan uji korelasi Bivariate pearson untuk mengetahui adanya hubungan antara curah hujan dan titik panas. Persamaan yang dapat digunakan dalam penelitian ini yaitu:

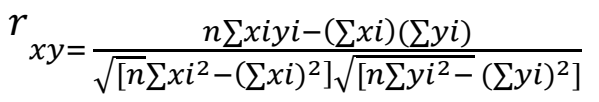

Keterangan:

$$
\begin{aligned}
r_{x y} & =\text { korelasi } \\
\mathrm{x} & =\text { variabel } 1 \\
\mathrm{y} & =\text { variabel } 2 \\
\mathrm{n} & =\text { jumlah data }
\end{aligned}
$$

\section{HASIL DAN PEMBAHASAN}

\section{Kondisi Umum Lokasi Penelitian}

Kabupaten Aceh Barat merupakan salah satu kabupaten yang terletak di bagian barat Provinsi Aceh dengan Ibukota Meulaboh memiliki luas wilayah darat $2.927,95 \mathrm{~km}^{2}$, wilayah lautan sejauh 12 mil seluas $957,38 \mathrm{~km}^{2}$ dan garis pantai sepanjang $54,84 \mathrm{~km}^{2}$. Berdasarkan letak astronomis, Kabupaten Aceh Barat terletak di sebelah utara khatulistiwa yakni antara 0406' - 0447' Lintang Utara dan 95 ${ }^{\circ} 52^{\prime}$ - 96 $96^{\circ}$ ' Bujur Timur. Secara administratif Kabupaten Aceh Barat terbagi dalam 12 Kecamatan, yaitu Johan Pahlawan, Samatiga, Bubon, Arongan Lambalek, Woyla, Woyla Barat, Woyla Timur, Kaway XVI, Meureubo, Pante Ceureumen, Panton Reu dan Sungai Mas (BPS Aceh Barat 2020). Batas administrasi wilayah Kabupaten Aceh Barat berbatasan dengan kabupaten-kabupaten: sebelah utara dengan Kabupaten Aceh Jaya, Kabupaten Pidie dan Kabupaten Aceh Tengah, sebelah selatan dengan Samudera Hindia dan Kabupaten Nagan Raya, sebelah timur dengan Kabupaten Aceh Tengah dan Kabupaten Nagan Raya serta sebelah barat dengan Samudera Hindia dan Kabupaten Aceh Jaya.

\section{Sebaran Titik Panas (Hotspot)}

Titik panas atau hotspot adalah istilah untuk sebuah pixel yang memiliki nilai temperatur di atas ambang batas (threshold) tertentu dari hasil interpretasi citra satelit, yang dapat digunakan sebagai indikasi kejadian kebakaran hutan dan lahan (KLHK 2016). Analisis data titik panas menggunakan data dengan tingkat kepercayaan $\geq 50 \%$. Berdasarkan titik panas yang terpantau dari satelit MODIS dapat diketahui bahwa selama rentang waktu dari tahun 2014 hingga tahun 2019, pada daerah Kabupaten Aceh Barat selalu

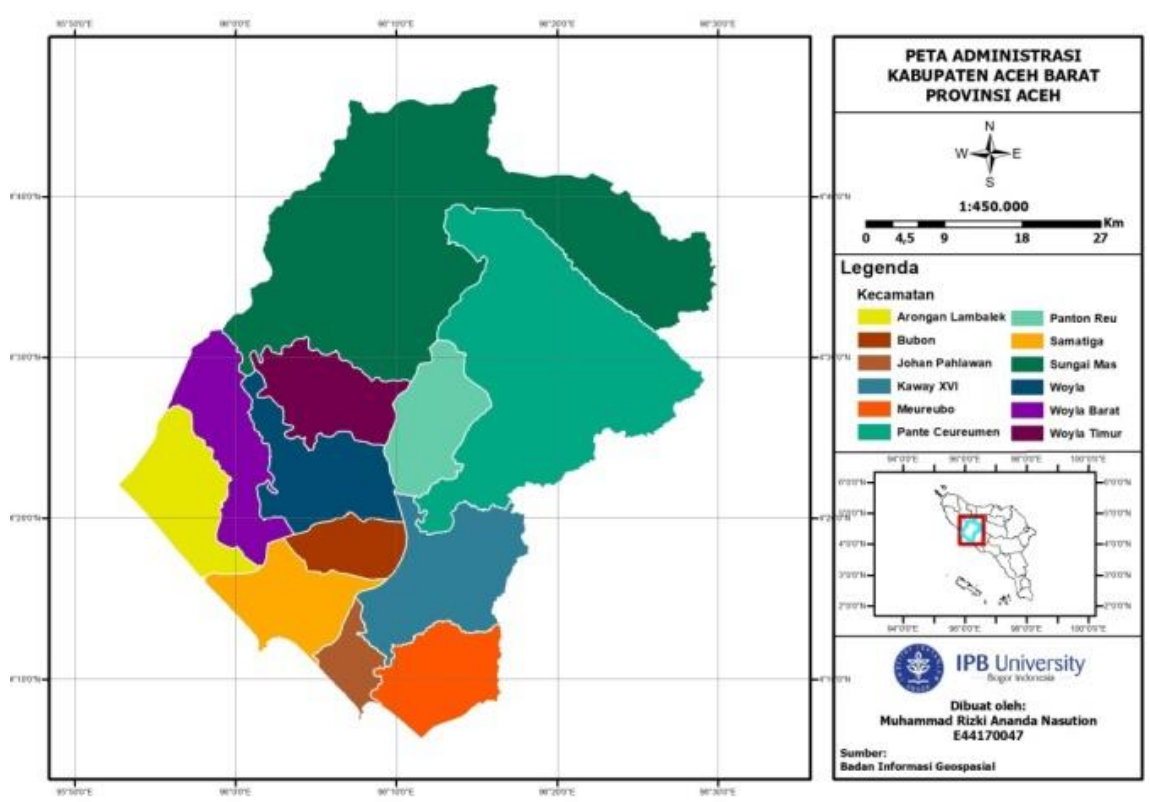

Gambar 1 Peta Wilayah Administrasi Kabupaten Aceh Barat 
terdapat kemunculan titik panas dengan jumlah yang tidak sama setiap tahunnya seperti terlihat pada Gambar 2.

Jumlah titik panas tahunan pada tahun 2014-2019 yaitu sebanyak 576 titik, pada tahun 2014 sebanyak 372 titik, menurun drastis di tahun 2015 dan tahun 2016 yaitu berturut-berturut menjadi 21 titik dan 32 titik. Tahun 2017 titik panas kembali meningkat secara drastis yaitu sebanyak 116 titik dan pada tahun 2018 serta tahun 2019 kembali menurun yaitu berturut-turut menjadi sebanyak 15 titik dan 20 titik. Berdasarkan data tersebut dapat diketahui bahwa pada tahun 2014 dan tahun 2017 titik panas yang terpantau oleh satelit MODIS pada wilayah Kabupaten Aceh Barat mencapai jumlah diatas 100 titik per tahun sehingga dapat dikatakan tinggi jika dibandingkan dengan kemunculan titik panas pada tahun yang lainnya. Menurut Syaufina et al. (2014) faktor iklim seperti curah hujan, kelembaban dan suhu dapat mempengaruhi sebaran titik panas pada suatu wilayah serta fenomena meteorologis seperti ENSO (El Nino Southern Oscillation) dan IOD (Indian Ocean Dipole).

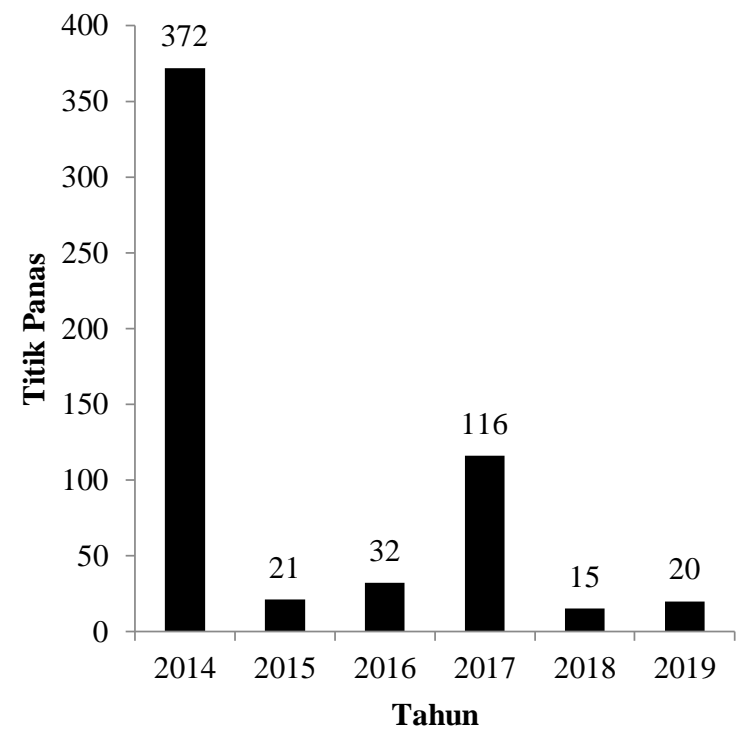

Gambar 2 Jumlah titik panas tahun 2014-2019 di Kabupaten Aceh Barat
Berdasarkan Gambar 3, jumlah titik panas di awal tahun berada dalam intensitas yang tinggi pada tahun 2014, namun pada tahun 2015-2019 menunjukkan intensitas yang rendah pada awal tahun. Sebaran titik panas tertinggi pada tahun 2014 terjadi pada bulan Februari-Maret yaitu sebanyak 131 titik dan 172 titik. Sebaran titik panas tidak ditemukan pada bulan April, Oktober sampai Desember. Selanjutnya, pada tahun 2015 sampai 2019 terlihat kemunculan titik panas tertinggi di bulan Juni sampai Agustus. Terlihat bahwa pada tahun 2017 di bulan Juli dan Agustus terjadi kemunculan titik panas yaitu berturut-turut sebanyak 38 titik dan 22 titik. Sebaran titik panas terbanyak yang terjadi diakibatkan oleh faktor kesengajaan atau ketidaksengajaan. Hal tersebut sesuai dengan Sulistyowati (2004) dalam penelitiannya bahwa titik panas banyak dijumpai pada bulan dengan iklim yang kering. Saat bulan dengan iklim yang kering inilah masyarakat maupun perusahaan kehutanan dan perkebunan melakukan kegiatan pembersihan lahan dengan cara dibakar. Selanjutnya, sebaran titik panas mengalami penurunan dari bulan September sampai Desember yang diakibatkan oleh kondisi iklim mulai

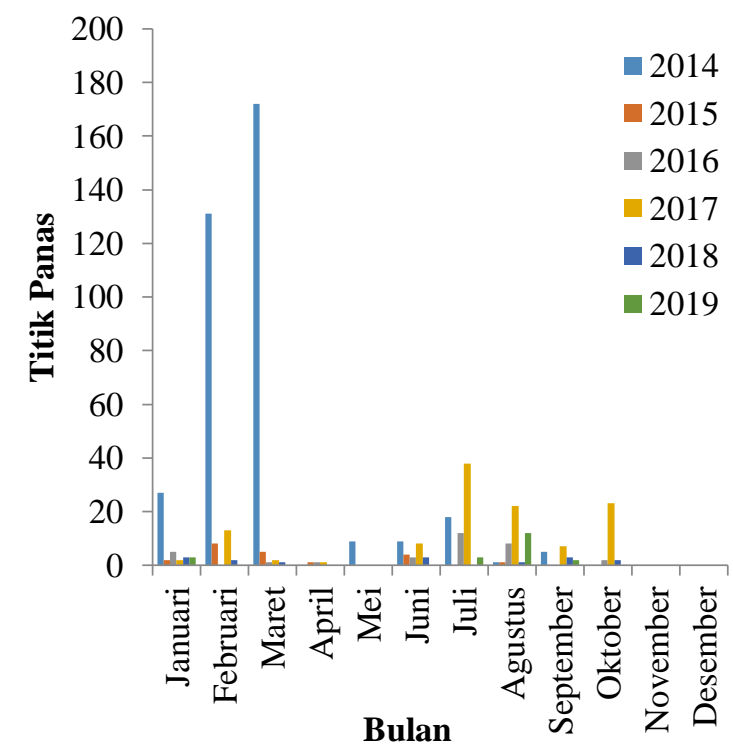

Gambar 3 Sebaran titik panas bulanan tahun 20142019 di Kabupaten Aceh Barat

Tabel 1 Jumlah titik panas berdasarkan wilayah Kecamatan

\begin{tabular}{|c|c|c|c|c|c|c|c|}
\hline \multirow{2}{*}{ Kecamatan } & \multicolumn{6}{|c|}{ Tahun } & \multirow{2}{*}{ Jum-lah } \\
\hline & 2014 & 2015 & 2016 & 2017 & 2018 & 2019 & \\
\hline Arongan Lambalek & 28 & 3 & 12 & 13 & 0 & 0 & 56 \\
\hline Bubon & 59 & 0 & 0 & 3 & 0 & 9 & 71 \\
\hline Johan Pahlawan & 57 & 3 & 3 & 38 & 2 & 4 & 107 \\
\hline Kaway XVI & 42 & 0 & 1 & 18 & 1 & 1 & 63 \\
\hline Meureubo & 16 & 3 & 5 & 5 & 1 & 0 & 30 \\
\hline Pantai Ceuremen & 7 & 1 & 0 & 6 & 2 & 1 & 17 \\
\hline Panton Reu & 4 & 0 & 0 & 2 & 0 & 0 & 6 \\
\hline Samatiga & 108 & 4 & 1 & 14 & 3 & 1 & 131 \\
\hline Sungai Mas & 6 & 0 & 6 & 5 & 3 & 0 & 20 \\
\hline Woyla & 12 & 5 & 2 & 4 & 1 & 0 & 24 \\
\hline Woyla Barat & 24 & 2 & 2 & 5 & 0 & 4 & 37 \\
\hline Woyla Timur & 9 & 0 & 0 & 3 & 2 & 0 & 14 \\
\hline
\end{tabular}

memasuki musim curah hujan yang tinggi. 


\section{Sebaran Titik Panas Berdasarkan WilayahKecamatan}

Titik panas yang terjadi di Kabupaten Aceh Barat selama tahun 2014 sampai 2019 menunjukkan bahwa wilayah yang memiliki titik panas tertinggi adalah Kecamatan Johan Pahlawan dan Kecamatan Samatiga. Hal ini ditandai dengan jumlah titik panas dalam 6 tahun terakhir jauh lebih banyak daripada kecamatan lainnya, yaitu dengan jumlah berturut-turut sebanyak 107 titik panas dan 131 titik panas.

Kedua kecamatan ini juga terdapat lahan gambut dimana aktivitas masyarakat dan perusahaan membuka lahan untuk perkebunan dengan penerapan Zero Burning masih sulit dilaksanakan bagi masyarakat umum. Sedangkan Kecamatan Panton Reu, Pantai Ceureumen dan Woyla Timur merupakan wilayah dengan kemunculan titik panas terendah dan jarang muncul disetiap tahunnya, yaitu dengan jumlah berturut-turut sebanyak 6 titik, 17 titik dan 14 titik. Hal ini disebabkan karena ketiga wilayah tersebut merupakan wilayah yang terdapat hutan dengan fungsi kawasan hutan lindung dan memiliki topografi yang tinggi daripada kecamatan lainnya, sehingga aktivitas masyarakat atau perusahaan yang dapat memicu kemunculan titik panas akibat pembukaan lahan dapat dihindari.

\section{Sebaran Titik Panas pada Tipe Tanah}

Kemunculan titik panas di Kabupaten Aceh Barat terdapat pada dua tipe tanah, yaitu tanah gambut dan tanah mineral. Selama rentang waktu tahun 2014-2019 diketahui bahwa jumlah titik panas terpantau sebanyak 576 titik panas. Gambar 4 menunjukkan persentase sebaran titik panas berdasarkan kedua tipe tanah. Sebanyak 366 titik panas atau 64\% ditemukan pada tanah bergambut, sedangkan 210 titik panas atau $36 \%$ ditemukan pada tanah mineral.

Lahan gambut memiliki sifat irreversible drying, sehingga jika suatu lahan sudah kering tidak dapat menyerap air. Salah satu faktor penting yang mengakibatkan mudahnya terbakar dari bahan tanah gambut yaitu kelembaban tanah dan kandungan air. Berdasarkan penelitian Thoha (2019) bahwa penyebaran api di lahan gambut dipengaruhi oleh curah hujan,

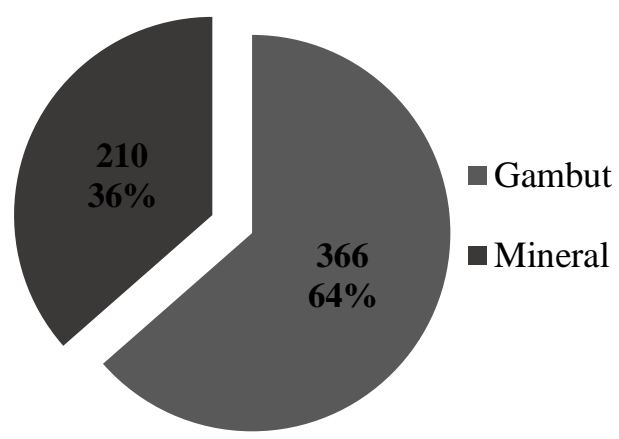

Gambar 4 Persentase sebaran titik panas berdasarkan tipe tanah tahun 2014-2019 di Kabupaten Aceh Barat dengan meningkatnya curah hujan maka ketersediaan air di dalam lahan gambut bertambah yang akan menyebabkan lahan tersebut untuk terbakar menjadi sulit.

\section{Sebaran Titik Panas pada Penutupan Lahan}

Sebaran titik panas selama tahun 2014-2019 diketahui bahwa jumlah titik panas paling banyak ditemukan pada penggunaan tutupan lahan berupa belukar rawa, sedangkan jumlah titik panas paling sedikit ditemukan pada penggunaan tutupan lahan berupa hutan lahan kering primer. Sebaran titik panas pada masing-masing penggunaan tutupan lahan secara lengkap tersaji pada Gambar 5.

Kemunculan titik panas paling banyak secara kesuluruhan selama tahun 2014 hingga tahun 2019 ditemukan pada lahan belukar rawa yaitu sebanyak 126 titik. Kemunculan titik panas pada penggunaan lahan belukar rawa terjadi diakbatkan oleh adanya penyiapan lahan oleh masyarakat dan perusahaan perkebunan yang berada di Kabupaten Aceh Barat. Menurut Mulyoutami et al. (2010) bahwa masyarakat di Aceh menebang hutan untuk menanam nilam dengan mempersiapkan lahan dengan proses pembakaran, memberakan lahannya dan membuka areal hutan lain bila produksi nilam menurun.

Penggunaan tutupan lahan lainnya yang juga ditemukan titik panas terbanyak adalah pada penggunaan tutupan lahan berupa perkebunan, yaitu terpantau sebanyak 102 titik panas. Kegiatan pembukaan kawasan perkebunan biasanya menggunakan metode pembakaran agar dapat dilakukan secara murah dan mudah serta menghasilkan bahan mineral yang siap diserap oleh tanaman (Saharjo 1999). Menurut Mardiani (2014) Kabupaten Aceh Barat

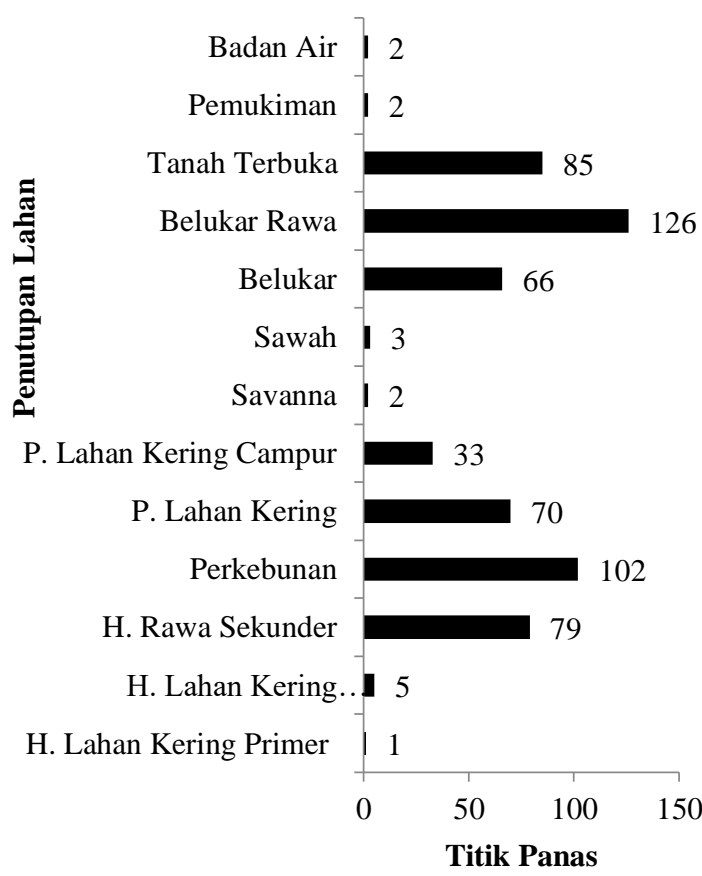

Gambar 5 Titik panas tipe penutupan lahan tahun 2014-2019 di Kabupaten Aceh Barat 
merupakan salah satu daerah di Provinsi Aceh yang memiliki jumlah titik panas tertinggi karena masih didominasi oleh hutan dan adanya kegiatan konversi lahan hutan menjadi lahan pertanian maupun perkebunan.

Titik panas juga ditemukan mendominasi pada penggunaan tutupan lahan lainnya yaitu pada tanah terbuka dengan jumlah titik panas sebanyak 85 titik panas, hutan rawa sekunder sebanyak 79 titik panas, pertanian lahan kering terpantau sebanyak 70 titik panas dan belukar sebanyak 66 titik panas. Menurut Syaufina dan Hafni (2018) menyebutkan bahwa lahan tidak produktif seperti semak belukar rawa dan tanah kosong dapat meningkatkan peluang terjadinya kebakaran hutan dan lahan.

\section{Hubungan antara Titik Panas dengan Curah Hujan}

Kondisi iklim di Kabupaten Aceh Barat termasuk dalam kategori daerah sub-tropis yang terdiri dari dua musim iklim, yaitu musim hujan dan musim kemarau. Curah hujan merupakan unsur iklim yang mewakili hubungan korelasi tinggi dengan kejadian kebakaran hutan dan lahan serta merupakan faktor yang paling tinggi dalam menentukan akumulasi bahan bakar (Syaufina 2008).

Gambar 6 menunjukkan bahwa hampir seluruh bulan dari Januari hingga Desember, titik panas (hotspot) bulanannya berbanding terbalik dengan curah hujan bulanan. Apabila curah hujan naik, maka jumlah titik panas yang ditemukan akan menurun serta sebaliknya apabila curah hujan menurun maka titik panas yang ditemukan juga naik. Jumlah titik panas tertinggi pada tahun 2014 terjadi pada bulan FebruariMaret, sedangkan pada tahun 2015 hingga 2019 terjadi pada bulan Juni, Juli dan Agustus dimana pada bulan

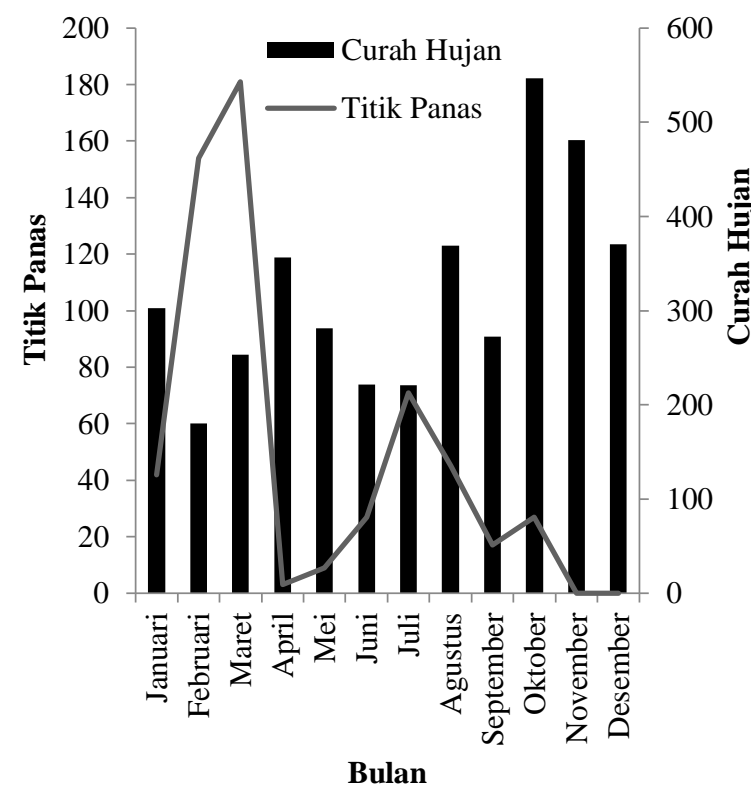

Gambar 6 Jumlah titik panas bulanan dan curah hujan bulanan di Kabupaten Aceh Barat tahun 2014-2019 tersebut terjadi musim kemarau di Aceh Barat. Bulan Oktober hingga Desember terlihat merupakan puncak dari banyaknya curah hujan Cuaca di Kabupaten Aceh Barat. Hal ini menyebabkan titik panas pada bulan Oktober hingga Desember mengalami penurunan dari bulan-bulan sebelumnya. Sehingga hal ini juga sesuai dengan penelitian Syaufina dan Sukmana (2008) bahwa peningkatan dan penurunan jumlah titik panas pada bulan-bulan tertentu akan berkaitan dengan peningkatan dan penurunan jumlah curah hujan. Hal ini dikarenakan curah hujan dapat menyebabkan kadar air pada suatu bahan bakar meningkat, sehingga bahan bakar sulit untuk dibakar.

Berdasarkan hasil uji korelasi antara jumlah titik panas dan curah hujan mendapatkan $P$-value sebesar 0.082 yang berada diatas batas kesalahan maksimal yang digunakan sebesar 0.05. Hasil uji ini menunjukkan bahwa curah hujan tidak dapat digunakan dalam pendugaan jumlah titik panas (hotspot) di Kabupaten Aceh Barat. Hasil uji korelasi ini sesuai dengan penelitian Syaufina dan Hafni (2018) bahwa hasil uji korelasi antara curah hujan dan titik panas memiliki nilai $P$-value melewati batas kesalahan maksimal 0.05 . Hal ini dikarenakan data kemunculan titik panas tidak menyebar secara normal dikarenakan perbedaan waktu kejadian. Diluar faktor iklim juga dapat mempengaruhi kemunculan titik panas seperti aktivitas manusia dalam penyiapan lahan dengan cara tebas bakar serta kelalaian dalam mematikan api. Hasil analisis korelasi antara curah hujan dan titik panas menunjukan nilai korelasi pearson sebesar -0.521 . Notasi negatif (-) pada hasil uji korelasi tersebut menunjukkan arah kedua hubungan antara curah hujan dengan titik panas mempunyai hubungan terbalik. Hubungan terbalik memberikan arti bahwa kenaikan curah hujan akan berpotensi menurunkan jumlah titik panas dan sebaliknya, penurunan curah hujan akan berpotensi meningkatkan jumlah titik panas.

\section{SIMPULAN DAN SARAN}

\section{Simpulan}

Jumlah titik panas tahunan pada tahun 2014 hingga tahun 2019 yaitu sebanyak 576 titik panas di Kabupaten Aceh Barat. Tahun 2014 dan tahun 2017 titik panas yang terpantau oleh satelit MODIS pada wilayah Kabupaten Aceh Barat mencapai jumlah diatas 100 titik per tahun sehingga dapat dikatakan tinggi jika dibandingkan dengan kemunculan titik panas pada tahun yang lainnya. Kecamatan Johan Pahlawan dan Kecamatan Samatiga merupakan wilayah yang paling banyak menyumbangkan jumlah titik panas. Sebanyak 366 titik panas atau $64 \%$ ditemukan pada tanah bergambut, sedangkan 210 titik panas atau $36 \%$ ditemukan pada tanah mineral. Jumlah titik panas paling banyak ditemukan pada penggunaan tutupan lahan berupa belukar rawa, sedangkan jumlah titik panas paling sedikit ditemukan pada penggunaan tutupan lahan berupa hutan lahan kering primer. Hasil uji korelasi menunjukkan curah hujan dengan titik panas tidak memiliki korelasi dengan arah korelasi negatif, 
bahwa penurunan curah hujan diikuti dengan kenaikan titik panas, sebaliknya peningkatan curah hujan diikuti dengan penururnan titik panas.

\section{Saran}

Perlu adanya ground check atau pemeriksaan langsung di lapangan untuk mengetahui kondisi penutupan lahan, tutupan lahan gambut dan mineral dan faktor iklim di lokasi penelitian terhadap distribusi titik panas. Selain itu, perlu dilakukan uji lanjutan terhadap hubungan faktor iklim lainnya, seperti udara, kelembaban, suhu dan kecepatan angin.

\section{DAFTAR PUSTAKA}

[BPS] Badan Pusat Statistik Kabupaten Aceh Barat. 2020. Kabupaten Aceh Barat Dalam Angka 2020. Meulaboh (ID): BPS Kabupaten Aceh Barat.

Giglio L, Schroeder W, Justice CO. 2016. The collection 6 MODIS active fire detection algorithm and fire products. Remote Sensing of Environment, 178, 31-41.

[KLHK] Kementerian Lingkungan Hidup dan Kehutanan Republik Indonesia. 2016. Peraturan Menteri Lingkungan Hidup dan Kehutanan Nomor P.32/ MenLHK/ Setjen / Kum.1 / 3 / 2016 tentang Pengendalian Kebakaran Hutan dan Lahan. Jakarta (ID): Kementerian Lingkungan Hidup dan Kehutanan.

Mardiani D. 2014. Hubungan curah hujan dan titik panas (hotspot) dalam kaitannya dengan terjadinya kebakaran di Provinsi Aceh [skripsi]. Bogor (ID): Institut Pertanian Bogor.

Mulyoutami E, van Noordwijk M, Sakuntaladewi N, Agus F. 2010. Perbahan Pola Perladangan: Pergeseran persepsi mengenai para peladang di Indonesia. Bogor (ID): World Agroforestry Centre.

Saharjo BH, Husaeni EA, Kasno. 1999. Manajemen Penggunaan Api dan Bahan Bakar dalam
Penyiapan Lahan di Areal Perladangan Berpindah. Bogor (ID): Fakultas Kehutanan IPB.

Saharjo BH. 2003. Segitiga Api. Di dalam: Suratmo FG, Husaeni EA, Jaya INS, editor. Pengetahuan Dasar Pengendalian Kebakaran Hutan. Bogor (ID): Fakultas Kehutanan IPB Pr.

Sulistyowati S. 2004. Hubungan unsur iklim dan titik panas (hotspot) di Kabupaten Ogan Komering Ilir, Provinsi Sumatera Selatan periode tahun 2001-2002 [skripsi]. Bogor (ID): Institut Pertanian Bogor.

Syaufina L, Hafni DAF. 2018. Variabilitas iklim dan kejadian kebakaran hutan dan lahan gambut di Kabupaten Bengkalis, Provinsi Riau. Jurnal Silvikultur Tropika 9(1): 60-68.

Syaufina L, Siwi R, Nurhayati AD. 2014. Perbandingan sumber hotspot sebagai indikator kebakaran hutan dan lahan gambut dan korelasinya dengan curah hujan di Desa Sepahat, Kabupaten Bengkalis, Riau. Jurnal Silvikultur Tropika 5(2): 113-118.

Syaufina L, Sukmana A. 2008. Tinjauan Penyebab Utama Kebakaran Hutan di Daerah Tangkapan Air Danau Toba. Laporan Akhir Studi Program ITTO PD 394/06 Rev. 1 (F). Bogor (ID): Pusat Penelitian dan Pengembangan Hutan Konservasi Alam.

Syaufina L. 2008. Kebakaran Hutan dan Lahan di Indonesia: Perilaku Api, Penyebab, dan Dampak Kebakaran. Malang (ID): Bayumedia.

Thoha AS, Saharjo BH, Boer R, Ardiansyah M. 2019. Characteristics and causes of forest and land fires in Kapuas District, Central Kalimantan Province, Indonesia. Biodiversitas Journal of Biological Diversity 20(1): 110-117.

Wahyunto, Ritung S, Subagjo H. 2005. Map of Peatland Distribution Area and Carbon Content in Sumatra. Bogor (ID): Wetland International Indonesia Program and Wildlife Habitat Canada (WHC). 